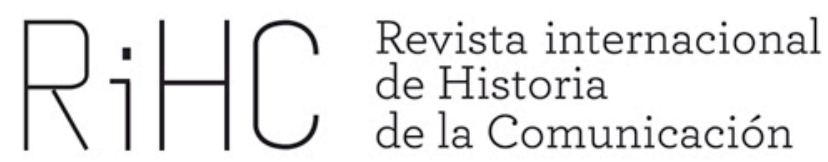

\title{
IFNI EN EL NO-DO (1943-1969)
}

DOI: http://dx.doi.org/10.12795/RiHC.2014.i02.04

Juan Manuel González Sáez

jugonzal36@gmail.com

Enviado: $\mathbf{3 0}$ de mayo de 2013

Aceptado: 3 de julio de 2013

Resumen: Este artículo analiza la presencia de Ifni en los noticiarios cinematográficos españoles entre 1943, fecha de creación de la entidad NO-DO, y 1969, año de la retrocesión del territorio a Marruecos. Este texto dedica especial atención al tratamiento informativo de la guerra de Ifni-Sahara analizando cuantitativa $y$ cualitativamente la visión del conflicto ofrecida a la opinión publica.

Palabras clave: Ifni, No-Do, guerra Ifni-Sahara

Abstract: This article analyzes the presence of Ifni in the spanish cinema newsreels (NODO), between 1943, date of creation of the entity NO-DO, and 1969, year of the delivery of the colony to Morocco. This text pays special attention to the informative coverage of the Ifni-Sahara's war, analyzing qualitatively and quantitatively the vision of the conflict presented to the public opinion.

Keywords: Ifni, No-Do, Ifni-Sahara war 


\section{Introducción}

Este artículo pretende ser una contribución a las investigaciones desarrolladas en torno al discurso y la retórica del régimen franquista sobre sus colonias africanas y sus relaciones con Marruecos difundidas a través de los medios de comunicación. Se ha centrado el objeto del análisis en los noticiarios del NO-DO sobre Ifni, territorio ocupado por España en 1934 e integrado en la denominada África Occidental Española. En concreto, se ha realizado un estudio de los contenidos de los noticiarios con referencias específicas a Ifni a lo largo del periodo comprendido entre la creación de este servicio cinematográfico en 1943 y la retrocesión del territorio a Marruecos en 1969. La investigación se ha focalizado especialmente en el análisis de la visión del conflicto bélico, del enemigo y de Marruecos durante la denominada "guerra ignorada" que se desarrolló entre noviembre de 1957 y junio de 1958 en Ifni y en el Sahara español.

La entidad Noticiarios y Documentales Oficiales NO-DO fue creada el 17 de diciembre de 1942. Una disposición de de la Vicesecretaría de Educación Popular de FET y de las JONS otorgó a este organismo oficial la exclusividad de la edición y explotación de los noticiarios cinematográficos en España. Asimismo determinó la obligatoriedad de la proyección del noticiario en todos los locales cinematográficos ${ }^{1}$. Esta situación de monopolio se mantendrá desde el primer número de NO-DO proyectado el 4 de enero de 1943 hasta el 22 de agosto de 1975. En 1951 NO-DO pasó a formar parte del Ministerio de Información y Turismo dependiendo en este organismo de la Dirección General de Cinematografía y Teatro tras su creación en $1952^{2}$.

Existen distintos estudios historiográficos que han analizado en profundidad el noticiario franquista. Se pueden destacar las investigaciones de Saturnino Rodríguez (1999), Ángel Hernández (2003) y muy especialmente los exhaustivos trabajos de Rafael R. Tranche y Vicente Sánchez Biosca (2000). Posteriormente Araceli Rodríguez Mateos (2008) realizó una tesis doctoral que, como ha observado Santiago de Pablo, es "un magnífico ejercicio de análisis de historia contemporánea por medio del cine". Esta investigación destaca por la metodología utilizada que aporta un completo modelo de análisis de contenidos del NO-DO.

\footnotetext{
${ }^{1}$ Véase Disposición de la Vicesecretaría de Educación Popular de F.E.T. y de las J.O.N.S., de 17 de septiembre de 1942, publicada en el BOE el 22 de diciembre de 1942.

${ }^{2}$ Es importante resaltar que en otros países europeos existieron noticiarios cuyas editoras eran empresas estatales o paraestatales. La diferencia era el régimen de concurrencia con producciones no estatales, propio de los países democráticos, o la exclusividad en la exhibición cinematográfica.
} 
No obstante, existe un vacío en relación al análisis historiográfico de las colonias africanas de Ifni y Sahara a través del estudio de las imágenes del noticiario NO-DO ${ }^{3}$. La presencia de los territorios del África Occidental Española en el noticiario franquista ha sido objeto de breves observaciones y análisis dentro de las investigaciones globales sobre el NO-DO, generalmente en relación al desarrollo del conflicto de IfniSahara durante el periodo 1957-1958. Rafael R. Tranche (2000: 112-113) ha realizado un breve apunte sobre el tratamiento informativo de la guerra de Ifni-Sahara. Mayor atención dedica Araceli Rodríguez (2008: 202-208) al análisis de las imágenes de la intervención del ejército en tierras africanas ${ }^{4}$. Sin embargo, los estudios más completos sobre las colonias de Ifni y Sahara en este noticiario se deben a Guadalupe Pérez (2004 y 2006), investigadora que realizó su tesis doctoral sobre información y propaganda colonial en estos territorios.

Por otra parte, la historiografía española sobre el Magreb contemporáneo, pese a las contribuciones de especialistas como, por ejemplo, Víctor Morales, Miguel Hernando de Larramendi, Susana Sueiro o Juan Bautista Vilar, sigue siendo "exigua" (Ybarra, 2007: 165-166), condicionada indudablemente por las limitaciones de consulta de algunos fondos (Morales, 2006: 362). En el caso de la guerra de Ifni, las dificultades de acceso a documentos existentes en los archivos españoles, como el Archivo General de la Administración o el Archivo Militar de Ávila, ha determinado el escaso número de investigaciones bien documentadas sobre el conflicto en este territorio colonial. La historiografía, sin querer ser exhaustivo en las referencias señaladas en este estado de la cuestión, se muestra dominada por los trabajos, ya clásicos, de unos pocos historiadores, con experiencia militar directa en las colonias africanas (Casas de la Vega, 1985, reedición 2008; Aguirre, 1993; Fernández-Aceytuno, 2001). En los últimos años han aparecido nuevas contribuciones de militares profesionales (Colldefors, 2007; Alonso, 2010; Bataller, 2012; López-Pozas, 2013), así como libros que recogen el testimonio y punto de vista, generalmente olvidado, de los soldados de reemplazo combatientes en esta guerra (Jorques, 2011). Simultáneamente han sido publicadas interesantes contribuciones, algunas de carácter más divulgativo, de investigadores no militares (Vidal, 2006; Segura Valero, 2006; Canales y Del Rey, 2010). Sin embargo, como señala Francesco Correale en una comunicación que ha estudiado la "literatura militar" sobre este conflicto entre 2001 y 2010, todavía es necesario "efectuar una descolonización del saber sobre la antigua África Española, abandonando la lógica militar y de militancia a favor de la científica" (Correale, 2010).

\footnotetext{
${ }^{3}$ Esta investigación limita su objeto de estudio a los noticiarios y no tiene en cuenta otros formatos periódicos de NO-DO. Por ejemplo, la revista Imágenes, cuya proyección no era obligatoria en las salas cinematográficas, dedicó diversos reportajes a Ifni y Sahara (Rodríguez Mateos, 2008: 202).

${ }^{4}$ En su estudio no analiza tres noticiarios que ofrecen información sobre la guerra de Ifni. En concreto, no hace referencia a los números 779 A, 779 B y 781 A.
} 
En definitiva, resulta de interés una investigación sobre Ifni a partir del NO-DO, una fuente documental todavía escasamente explotada. Este trabajo ha sido facilitado por el acceso on line al Archivo Histórico del NO-DO a través de la web de RTVE y de la Filmoteca Española (www.rtve.es/filmoteca/no-do) que permite la consulta a todas las ediciones realizadas de los noticiarios, salvo en el caso de unos pocos números de los que no se conservan negativos ni copias ${ }^{5}$. La versión beta de esta web cuenta con un buscador cuyos resultados para una mayor precisión requieren, tal y como se ha hecho durante esta investigación, ser complementados con búsquedas manuales y consultas de los programas que anunciaban el contenido de los noticiarios. Siguiendo algunas pautas metodológicas propuestas para el estudio de la historia filmada (Paz y Sánchez, 1999; Rodríguez Mateos, 2008: 245-249), junto con un breve estudio de los orígenes del NO-DO y del contexto histórico de Ifni, se ha realizado un análisis cuantitativo y cualitativo de los contenidos presentados por los noticiarios.

\section{Ifni: colonización y guerra}

En 1475 Diego García de Herrera estableció una torre-fuerte en las costas del Mar Menor de Berbería frente al archipiélago canario. Esta pequeña fortaleza y pesquería, cincuenta años después, fue abandonada tras los ataques de tribus saharianas. Cuatro siglos más tarde, en 1860 el tratado de Paz y Amistad entre España y Marruecos reconoció el derecho de nuestro país a ocupar junto a Santa Cruz de Mar Pequeña "el territorio suficiente para la formación de un establecimiento de pesquería" como el que históricamente se había poseído. Las antiguas posesiones españolas fueron ubicadas, en un proceso complejo y repleto de dudas sobre su emplazamiento real, en Ifni, un pequeño enclave $\left(1.500 \mathrm{~km}^{2}\right)$ en territorio marroquí ${ }^{6}$. Tras distintos proyectos fracasados, durante la Segunda República, en 1934, se decidió la ocupación efectiva del territorio. La misión fue desarrollada, de forma pacifica, por el coronel Fernando Capaz. Después de la Segunda Guerra Mundial, la relevancia estratégica de la zona impulsó que en 1946 España reforzase su presencia y que crease el África Occidental Española (AOE) integrada por Ifni, Tarfaya y el Sahara Español. Estos territorios, junto con la zona norte del Protectorado de Marruecos y las colonias del golfo de Guinea, formaban los dominios coloniales de nuestro país.

\footnotetext{
${ }^{5}$ Según R. Tranche, no existe copia de los noticiarios 100 B, 185 B, 187 B, 190 A y 366 A (Tranche, 2000: 74). En la versión beta de la web del Archivo Histórico del NO-DO se contempla la existencia de los noticiarios $15 \mathrm{~B}$ y $25 \mathrm{C}$ que creemos un error de la catalogación on line.

${ }^{6}$ Sobre las dificultades para la ubicación de Santa Cruz de Mar Pequeña e Ifni véase De la Serna, 2001 : 247-254 y Pérez, 2003: 207-222.
} 
El inicio de la época de la descolonización y la expansión del nacionalismo magrebí son factores clave que van a condicionar el futuro de la presencia española en África. No obstante, entre 1947 y 1955 el franquismo trató de reforzar la "acción de España" en el Protectorado y las colonias (Morales, 2006: 339-341). Pese a todos los esfuerzos, el nacionalismo marroquí, respaldado por los intereses de la política norteamericana en la zona, era imparable. En marzo de 1956 Marruecos consiguió su independencia de Francia, país con el que en 1912 había firmado el convenio que establecía el Protectorado y que había permitido a España "en subarriendo" ejercer su influencia en la zona (Madariaga, 2013: 88-89). Semanas después, España, siguiendo el ejemplo francés y, al mismo tiempo, por la presión e influencia norteamericana (Morales, 2006: 364), se vio obligada a conceder la independencia de su Protectorado el 7 de abril de 1956. Esta no contemplaba la cesión de Ifni o el Sahara. Sin embargo, desde ese momento, el país magrebí, donde la tesis expansionista del Gran Marruecos del partido nacionalista Istiqlal había ido recogiendo apoyo popular, reclamó reiteradamente la soberanía sobre estos territorios cuyos derechos, por otra parte, pueden ser cuestionados en el caso del Sahara (Ruiz Miguel, 1995).

El Ejército de Liberación o Yeicht Taharir, que antes de la independencia había mantenido una lucha guerrillera contra Francia y cuyas actividades habían sido toleradas por España, mantuvo sus objetivos de eliminación completa del colonialismo en el Gran Marruecos. A lo largo de 1957 la situación en Ifni y en el Sahara, ya enrarecida previamente por el intento de recaudación de impuestos sobre bienes de consumo (Casas de la Vega, 2008: 47-50), se va tornando conflictiva. Durante los meses de marzo y abril se produjeron continuos sabotajes de las líneas telefónicas que unían Sidi-Ifni con los puestos militares del interior de la provincia. Entre mayo y junio varios militares y policías indígenas fueron asesinados. El 10 de agosto se produjo un ataque armado contra el puesto español de Tiguist-Igurramen. El 21 de agosto el embajador marroquí reclamó en una nota dirigida al ministro de Asuntos Exteriores, Fernando Mạ Castiella, la devolución de Tarfaya e Ifni (Vilar, 2000: 402). Tras un periodo de relativa calma, el 25 de octubre un avión militar de reconocimiento fue tiroteado en Tafudart. La respuesta española consistió en el bombardeo de algunas partidas. En las mismas fechas, tras las reuniones mantenidas entre Castiella y el ministro de Asuntos Exteriores, Ahmed Balafrej, el gobierno marroquí volvió a reclamar la entrega de Ifni. España respondió negativamente el 5 de noviembre (Suárez, 2005: 514). La diplomacia fue sustituida por las agresiones.

El 23 de noviembre de 1957 comenzaron los ataques contra Sidi-Ifni. Más de doscientos combatientes del Ejército de Liberación trataron de tomar la ciudad. El plan defensivo funcionó adecuadamente y la ofensiva guerrillera fue rechazada. Sin embargo, la situación era mucho más complicada en los puestos aislados. Algunas posiciones, como Tamucha, Tabelcut, Hameiduch o Bifurna, cayeron en manos de las bandas armadas y se produjeron bajas españolas. Mientras se ejecutaba un plan 
defensivo centrado en garantizar la seguridad de Sidi Ifni, a lo largo del mes de diciembre se desarrollaron con éxito las operaciones de rescate de los puestos atacados. Paralelamente, los ataques de las bandas armadas también se extendieron al Sahara. El 13 de enero de 1958 resultaron muertos 48 legionarios en los combates de Edchera. La colaboración militar de Francia, país que padecía las amenazas y agresiones del Ejército de Liberación en Mauritania, fue decisiva para resolver los problemas españoles en el Sahara. Tras una gran ofensiva, coordinada con el ejército francés, el último combate, aunque siguieron existiendo pequeños incidentes durante meses, tuvo lugar en febrero. El 1 de abril de 1958 se alcanzó el acuerdo hispanomarroquí de Angra de Cintra por el que se devolvía Tarfaya al reino alauí. El 30 de junio las bandas armadas anunciaron el alto el fuego.

Estos acontecimientos demostraron las limitaciones de nuestro ejército y las dificultades para defender Ifni. El resultado del conflicto fue la pérdida del control de gran parte de la colonia. El territorio con soberanía española efectiva quedó reducido a la capital Sidi Ifni. Este repliegue, polémico entre algunos militares, fue una decisión tomada directamente por Franco para evitar bajas en puestos aislados (Platón, 2001: 238-239). Además, como se ha indicado, Marruecos recibió Tarfaya con el objeto de reducir las presiones de Mohamed V. Simultáneamente España, siguiendo el ejemplo del Portugal salazarista en sus colonias, creó la provincia de Ifni el 10 de enero de 1958. Este hecho, un "retroceso histórico incomprensible" en pleno proceso general de descolonización (De la Serna, 2001: 260) y que no contó con consenso unánime dentro del ministerio de Asuntos Exteriores (Morales, 1991: 177), no impidió que Marruecos incrementase sus presiones diplomáticas para apoderarse del territorio y que España, desde principios de los años sesenta, asumiese la inevitable futura cesión de Ifni (Franco Salgado-Araujo, 1976: 396; Piniés y Rubio, 2001: 60).

\section{Análisis cuantitativo: una presencia escasa}

Los resultados del análisis cuantitativo de las fuentes documentales del NO-DO demuestran, en primer lugar, el limitado interés de los noticiarios por Ifni, territorio pequeño, escasamente poblado y de casi nula actividad económica privada. En concreto, entre un total de 1.408 números de NO-DO y sus distintas ediciones $\mathrm{A}, \mathrm{B}$ y $\mathrm{C}$ que engloban 3.039 noticiarios producidos entre 1943 y 1969 (Tranche y Sánchez 
Biosca, 2000: 608$)^{7}$ se han localizado tan solo 26 noticiarios con referencias explícitas a Ifni ${ }^{8}$.

$\begin{array}{llllll}\text { № } & \text { Fecha } & \text { No } & \text { Fecha } & \text { No } & \text { Fecha } \\ \text { 408 A } & 30 / 10 / 1950 & 784 \mathrm{~A} & 13 / 01 / 1958 & 840 \mathrm{~B} & 09 / 02 / 1959 \\ \text { 493 B } & 16 / 06 / 1952 & 784 \mathrm{~B} & 13 / 01 / 1958 & 953 \mathrm{~B} & 10 / 04 / 1961 \\ 779 \mathrm{~A} & 9 / 12 / 1957 & 791 \mathrm{~B} & 03 / 03 / 1958 & 1.000 \mathrm{~A} & 05 / 03 / 1962 \\ 779 \mathrm{~B} & 9 / 12 / 1957 & 792 \mathrm{~A} & 10 / 03 / 1958 & 1.035 \mathrm{C} & 5 / 11 / 1962 \\ 781 \mathrm{~A} & 23 / 12 / 1957 & 794 \mathrm{~A} & 24 / 03 / 2958 & 1.083 \mathrm{~B} & 7 / 10 / 1963 \\ 782 \mathrm{~A} & 30 / 12 / 1957 & 796 \mathrm{~A} & 07 / 04 / 1958 & 1.211 \mathrm{~A} & 21 / 03 / 1966 \\ 782 \mathrm{~B} & 30 / 12 / 1957 & 801 \mathrm{~B} & 12 / 05 / 1958 & 1.215 \mathrm{~A} & 18 / 04 / 1966 \\ 783 \mathrm{~A} & 6 / 01 / 1958 & 818 \mathrm{~B} & 8 / 09 / 1958 & 1.384 \mathrm{~B} & 14 / 07 / 1969 \\ 783 \mathrm{~B} & 6 / 01 / 1958 & 825 \mathrm{~A} & 27 / 10 / 1958 & \text { Total: } 26 & \end{array}$

Tabla no 1: Noticiarios con referencias a Ifni entre 1943 y 1969.

El análisis temporal muestra que las informaciones contenidas en el NO-DO sobre esta colonia se concentran en el periodo 1957-1958 coincidente con la guerra de IfniSahara. Del total de referencias a Ifni más del $15 \%$ se generan en estos dos años. Antes de este conflicto, el NO-DO solo había dedicado dos noticiarios a este territorio. El primero era un reportaje sobre la visita de Franco a la colonia en 1950, un viaje para reafirmar la soberanía española ante las manifestaciones de solidaridad del sultán Mohamed V con el Istiqlal en esas mismas fechas y para presentar a España frente a los Estados Unidos "como un puente con el mundo islámico" (Cardona, 2003: 213). En este noticiario se exaltaba la figura del Caudillo como "el amigo de la tierra y de las gentes del Islam", así como la labor colonizadora española desarrollada en el territorio ${ }^{9}$. El otro reportaje se centraba en las fiestas populares celebradas en Ifni, que unían folklore autóctono y tradiciones ibéricas. Junto a imágenes de jinetes musulmanes, músicas y danzas indígenas se mostraba una parodia de corrida de $\operatorname{toros}^{10}$.

$\begin{array}{llllllll}\text { Año } & \text { Referencias } & \text { Ediciones } & \% & \text { Año } & \text { Referencias } & \text { Ediciones } & \% \\ 1943 & 0 & 85 & 0 \% & 1957 & 5 & 106 & 4,72 \%\end{array}$

\footnotetext{
${ }^{7}$ En la tabla de producción de noticiarios existe un error de detalle en la columna de totales anuales del año 1944. El dato correcto es 90 y no 30 como indica.

${ }^{8}$ En el noticiario $783 \mathrm{~A}$, que ofrece extractos del discurso de fin de año pronunciado por Franco, no hay una referencia explícita al término Ifni, a diferencia del contenido del noticiario $783 \mathrm{~B}$, pero el tema tratado es la guerra en el territorio africano. En el noticiario $1.083 \mathrm{~B}$ Ifni tan solo es citado como un punto de destino de la travesía de un buque recién flotado.

${ }^{9}$ N. 408 A, 30 de octubre de 1950. Franco visitó El Aaiún y Villa Cisneros durante el mismo viaje.

${ }^{10}$ N. 493 B, 16 de junio de 1952.
} 


$\begin{array}{llllllll}1944 & 0 & 90 & 0 \% & 1958 & 11 & 104 & 10,58 \% \\ 1945 & 0 & 75 & 0 \% & 1959 & 1 & 104 & 0,96 \% \\ 1946 & 0 & 59 & 0 \% & 1960 & 0 & 117 & 0 \% \\ 1947 & 0 & 104 & 0 \% & 1961 & 1 & 156 & 0,64 \% \\ 1948 & 0 & 104 & 0 \% & 1962 & 2 & 159 & 1,26 \% \\ 1949 & 0 & 104 & 0 \% & 1963 & 1 & 156 & 0,64 \% \\ 1950 & 1 & 104 & 0,96 \% & 1964 & 0 & 156 & 0 \% \\ 1951 & 0 & 104 & 0 \% & 1965 & 0 & 156 & 0 \% \\ 1952 & 1 & 106 & 0,94 \% & 1966 & 2 & 156 & 1,28 \% \\ 1953 & 0 & 104 & 0 \% & 1967 & 0 & 108 & 0 \% \\ 1954 & 0 & 104 & 0 \% & 1968 & 0 & 106 & 0 \% \\ 1955 & 0 & 104 & 0 \% & 1969 & 1 & 104 & 0,96 \% \\ 1956 & 0 & 104 & 0 \% & \text { Total } & 26 & 3.039 & 0,86 \%\end{array}$

Tabla no 2: Distribución temporal de los noticiarios con referencias a Ifni entre 1943 y 1969.

Esta investigación, dada la centralidad de la guerra en la presencia de Ifni en el NODO, se ha focalizado en el análisis del conflicto a través de las imágenes y textos de los noticiarios presentados en las pantallas cinematográficas. Una vez demostrado que, desde un punto de vista cuantitativo, el enfrentamiento bélico fue mostrado a los españoles, a continuación se evalúa el tratamiento cualitativo, indudablemente propagandístico, de los contenidos informativos.

\section{La guerra en el NO-DO}

EI NO-DO, como todo cine documental, "ficcionaliza" una realidad y construye una imagen, un objeto de significación, desde un punto de vista determinado ${ }^{11}$. En esta construcción se utilizan diferentes recursos técnicos y persuasivos. El tratamiento de la guerra de Ifni en los noticiarios cinematográficos españoles es un ejemplo preciso de persuasión vía exclusión temática. La opinión pública, la interpretación dominante del conjunto de ciudadanos, trató de ser condicionada a través de un proceso de fijación de contenidos que obviaba determinadas informaciones, como, por ejemplo, los muertos o las dificultades del ejército en combate ${ }^{12}$. El régimen franquista buscaba

\footnotetext{
${ }^{11}$ Una explicación sobre la tensión en las imágenes cinematográficas entre documental y ficción en Zunzunegui, 1984: 350-352.

${ }^{12}$ La existencia de opinión pública en el contexto de un régimen autoritario, con un sistema de censura $y$, por tanto, con un pluralismo informativo limitado, es lógicamente cuestionable. En este artículo, utilizamos este concepto para referirnos al conjunto coherente y estable de juicios que una colectividad comparten sobre una situación.
} 
minimizar el conflicto bélico ante la sociedad y optó por dar relevancia a aspectos secundarios de las operaciones frente a la imagen real del enfrentamiento ${ }^{13}$. El NO-DO siguió las pautas de la cobertura clásica de las guerras por parte de los noticiarios extranjeros (Rodríguez Mateos, 2008: 204). Lo importante no era analizar o explicar en profundidad lo que ocurría en el campo bélico sino mostrar "episodios favorables" al ejército propio. Esta observación es relevante frente a determinados análisis que tienden a resaltar la excepcionalidad propagandística del noticiario franquista. Medios públicos y propaganda están siempre vinculados, aunque lógicamente el pluralismo informativo de las sociedades democráticas permite atenuar los efectos de esta conjunción. En cualquier caso, el régimen franquista, mediante su sistema de censura, controlaba los contenidos de todos los medios de comunicación. El condicionamiento de las noticias fílmicas en el público estaba, asimismo, reforzado por la exclusividad del NO-DO en las salas de cine.

La cobertura informativa sobre la guerra en las pantallas cinematográficas, pese a los reiterados calificativos posteriores de guerra "ignorada" o "silenciada" (Segura, 2006; Vidal, 2006), existió aunque fue limitada. En el periodo comprendido entre noviembre de 1957, inicio del ataque a Sidi-Ifni, y junio de 1958, fecha oficial del fin del conflicto, las referencias a esta colonia aparecieron en catorce noticiarios.

En relación a los principales rasgos estructurales del NO-DO, el tiempo fílmico centrado en la guerra y sus diferentes aspectos fue amplio, con una dedicación del $17 \%$ de los 100 minutos totales de los noticiarios en el periodo álgido de los combates (noviembre 1957-marzo 1958). El orden de aparición de las informaciones sobre el conflicto también fue relevante. Las noticias de Ifni ocuparon en cinco ocasiones la última posición, ubicación con teóricos mayores efectos comunicacionales sobre los espectadores de las salas de cine.

\begin{tabular}{|llllll|}
\hline № & Fecha & $\begin{array}{c}\text { Duración } \\
\text { noticias de } \\
\text { Ifni (minutos) }\end{array}$ & $\begin{array}{c}\text { Duración total } \\
\text { del noticiario } \\
\text { (minutos) }\end{array}$ & $\begin{array}{c}\text { \% sobre } \\
\text { duración } \\
\text { total del } \\
\text { noticiario }\end{array}$ & $\begin{array}{c}\text { Número de bloques } \\
\text { informativos y orden } \\
\text { de noticias Ifni en el } \\
\text { programa }\end{array}$ \\
\hline 779 A & $9 / 12 / 1957$ & 1,44 & 9,56 & $15 \%$ & $6-5$ \\
779 B & $9 / 12 / 1957$ & 1,49 & 10,32 & $14 \%$ & $5-5$ \\
781 A & $23 / 12 / 1957$ & 0,44 & 10,10 & $4 \%$ & $8-4$ \\
782 A & $30 / 12 / 1957$ & 2,55 & 10,10 & $25 \%$ & $5-5$ \\
$782 B$ & $30 / 12 / 1957$ & 2,51 & 10,10 & $25 \%$ & $5-1$ \\
\hline 783 A & $6 / 01 / 1958$ & 1,51 & 10,05 & $15 \%$ & $7-7$ \\
783 B & $6 / 01 / 1958$ & 1,43 & 10,00 & $14 \%$ & $6-6$ \\
\hline
\end{tabular}

\footnotetext{
${ }^{13}$ Sobre la persuasión vía preselección de contenidos véase León, 1989: 187-190. En el análisis de los noticiarios las "ausencias" son tan relevantes como las repeticiones.
} 


$\begin{array}{llllll}784 \mathrm{~A} & 13 / 01 / 1958 & 2,05 & 10,12 & 20 \% & 6-4 \\ 784 \mathrm{~B} & 13 / 01 / 1958 & 2,05 & 10,16 & 20 \% & 6-3 \\ 791 \mathrm{~B} & 3 / 03 / 1958 & 1,46 & 10,04 & 15 \% & 6-6\end{array}$

Tabla no 3: Duración y orden de las noticias sobre la guerra de Ifni (noviembre 1957 - marzo 1958).

El discurso, en el NO-DO siempre dominado por la "preeminencia del texto" narrado sobre los elementos sonoros y visuales (Tranche y Sánchez Biosca, 2000: 118-119), minimizó la relevancia de los acontecimientos bélicos y transmitió una imagen de eficacia y organización del ejército que distaba, según se ha analizado posteriormente, de responder a la situación real de unas tropas mal equipadas y con serios problemas logísticos. El NO-DO justificó la presencia española en los territorios africanos aportando razones históricas y pruebas de la labor colonizadora desarrollada por España en favor de la población indígena.

Los textos, siempre con el característico tono ampuloso y artificioso propio de los guiones escritos por Alfredo Marqueríe y su equipo de redacción, fueron trabajados "con un cuidado extremo para ocultar la gravedad de la situación" y, al mismo tiempo, "afirmar la españolidad de la colonia" (Tranche y Sánchez-Biosca, 2000: 112-113). Las referencias a la guerra fueron ambiguas, minimizando, en línea con la opinión de Franco (Franco Salgado-Araujo, 1976: 223), los hechos y sin profundizar en el origen o motivaciones del Ejército de Liberación. El NO-DO, sometido al control externo estatal, aunque en esa época parece que no recibía consignas directas del poder político sobre sus contenidos, se alineó con el discurso oficial ${ }^{14}$. Esta guerra demostró que cuando el Régimen lo precisaba, en palabras de Rafael Tranche, "el NO-DO podía reverdecer su maquinaria propagandística". La estrategia propagandística en el NO-DO, en contraste con otros medios de comunicación, no fue la de culpabilizar del conflicto al comunismo internacional, sino la de "primar los elementos evasivos y el ensalzamiento de las acciones de los Ejércitos" (Pérez, 2006: 188).

La respuesta informativa a los acontecimientos bélicos, contrariamente a lo que han señalado algunos investigadores, fue ágil. Aunque determinar el inicio del conflicto de Ifni-Sahara es complejo, existe cierto consenso historiográfico por situar la fecha del 23 de noviembre de 1957 como el momento de arranque de la guerra, aunque ya habían existido numerosos incidentes violentos previos, tras el ataque a Sidi Ifni ${ }^{15}$. Teniendo en cuenta este dato, el NO-DO, pese a sus limitaciones técnicas y la complejidad de sus

\footnotetext{
${ }^{14}$ Según el testimonio de sus directivos, no había consignas directas del poder. Existía una autocensura de los guionistas que parecían conocer los límites informativos de los noticiarios de acuerdo a las orientaciones deseadas por las autoridades. Véase Rodríguez Mateos, 2008: 24-25.

${ }^{15}$ El 27 de noviembre se publicó la primera información oficial sobre el conflicto en la prensa. Véase “Nota del Ministerio del Ejército", ABC, 27 de noviembre de 1957. Un día antes, ya había aparecido alguna referencia a los ataques. Véase Carlos Sentís, "La conferencia del puré de guisantes", La Vanguardia Española, 26 de noviembre.
} 
procesos de producción, dio respuesta informativa rápida a estos acontecimientos ya que las primeras referencias a las "agresiones de las bandas armadas" aparecieron en los noticiarios 779 A y 779 B estrenados el 9 de diciembre de $1957^{16}$. Los guiones habían sido redactados, como ocurre en otras muchas informaciones del NO-DO, siguiendo el esquema contrario a la habitual fórmula de construcción de las noticias. En vez de utilizar la técnica de la pirámide invertida, basada en presentar la información ordenada en sentido decreciente según su grado de interés periodístico, los primeros noticiarios que abordan la guerra se inician con datos genéricos sobre Ifni dejando para su cierre las breves referencias al conflicto bélico. Estos relatos fílmicos parecen "reportajes turísticos" (Tranche y Sánchez-Biosca, 2000: 113). Por ejemplo, en el noticiario 779 A se hace una larga introducción sobre el territorio de Ifni y la labor colonizadora desarrollada por España. El guión dedica tan solo unas escasas palabras finales a señalar la alteración de la situación de "paz" y "progreso" por parte de elementos ajenos al territorio. El noticiario 779 B, que titula la información del conflicto como "Paisajes de Ifni", sigue esta misma línea convirtiéndose en un autentico reportaje sobre la labor colonizadora española en un territorio escasamente integrado con la metrópoli y, probablemente, con nulo conocimiento de su historia o situación geográfica por gran parte de los españoles. En las más de 200 palabras del texto leído por el locutor, solo 21 tienen relación con el conflicto bélico:

El territorio de Ifni pertenece al África Occidental Española. Tiene una superficie de 1.500 kilómetros cuadrados y 130 kilómetros de frontera que le separa del reino de Marruecos. Tierras sin cultivar, edificios de adobe y un nivel de vida y de cultura casi al margen de la historia encontró España en Ifni. Allí está desde principios del siglo XV y hace poco más de 20 años que fue ocupado materialmente habiendo desarrollado nuestra patria en este tiempo una intensa labor de progresos sanitarios, técnicos y administrativos que fueron apreciados $\mathrm{y}$ agradecidos por los baamaranis $\mathrm{y}$ envidiados por las tribus colindantes. Lo que en 1934 era una alcazaba semiderruida se transformó en la moderna ciudad de Sidi Ifni, incorporada al progreso y a la civilización. Cuenta el territorio con seis establecimientos sanitarios y 13 escuelas primarias de una asistencia media de más de 400 alumnos, al mismo tiempo que en el desierto fueron levantados poblados y granjas. España supo establecer en Ifni la herencia pura de su desinteresada empresa de colonización. La plena soberanía sobre Ifni se nos había concedido en el tratado de paz y amistad con Marruecos de 1860. Ifni, territorio de nuestra soberanía, no estaba incluido en el acuerdo por el cual España ponía fin a su protectorado y el ataque de las bandas armadas ha

\footnotetext{
${ }^{16}$ Araceli Rodríguez señala que la cobertura de la guerra se inició casi un mes después del ataque sorpresa del Ejecito de Liberación con los reportajes 782 A y B. Como indicamos, es importante precisar que ya se habían incluido referencias a las agresiones armadas en los números 779 A, 779 B y 781 A.
} 
demostrado que el gobierno de Rabat carece de autoridad sobre los territorios colindantes.

En el noticiario $782 \mathrm{~A}$, después de un confuso texto que parece dar entrada a otro reportaje turístico, se presentan las únicas imágenes de las tropas españolas combatiendo ${ }^{17}$. El NO-DO muestra baterías de artillería y armas automáticas disparando. Además, prueba de la existencia de un conflicto real, se ofrecen escenas de soldados heridos siendo adecuadamente evacuados por vía aérea. El resto de las informaciones visuales sobre la guerra en otros noticiarios son campamentos militares bien organizados, centinelas alerta, exhibiciones militares de las fuerzas paracaidistas, armas capturadas al enemigo o prisioneros marroquíes que tratarán de demostrar el control y dominio español.

Mientras que la información concreta sobre el conflicto y los combates es escasa, el NO-DO dedica gran atención a aspectos secundarios como el envío del aguinaldo a los soldados $^{18}$, el abastecimiento de Sidi Ifni por vía marítima ${ }^{19}$ o la visita de artistas españoles a los campamentos militares - Carmen Sevilla rodeada de soldados es una de las imágenes más populares de esta guerra- en las navidades de $1957^{20}$. A diferencia de la prensa que ofrece datos, aunque sean los facilitados por el ministerio del Ejército, sobre los combatientes españoles muertos, el noticiario omite este tipo de informaciones negativas ${ }^{21}$. En este sentido, la visión de los hechos ofrecida por el NODO es calificada, en una investigación sobre el papel de los medios de comunicación ante las crisis bélicas españolas, como puro "estilo Fenton", en relación a la obra de Roger Fenton, considerado el primer fotógrafo de guerra, cuyo reportaje sobre la guerra de Crimea ofrecía una imagen totalmente ajena a la realidad de los sufrimientos y muerte de los combatientes (Gómez Martínez y Encinar, 2010: 71).

\footnotetext{
${ }^{17}$ La voz en off pasa bruscamente del reportaje turístico al bélico: "He aquí algunos aspectos de Sidi Ifni rodados por los operadores de NO-DO. En la plaza de España el busto elevado a la memoria del coronel Capaz. Fuerzas de Infantería pertenecientes al grupo de tiradores de Ifni no 1 avanzan para consolidar sus bases de operaciones".

${ }^{18}$ N. 781 A, 23 de diciembre de 1957.

${ }^{19}$ N. 782 B, 30 de diciembre de 1957.

${ }^{20}$ N. 784 B, 13 de enero de 1958.

${ }^{21}$ En la prensa se pueden encontrar datos, incompletos, sobre las bajas en los combates pese a los calificativos de guerra ignorada o silenciada. Los periódicos difundieron las notas oficiales con los partes de bajas e informaciones diversas sobre los funerales y homenajes en memoria de los militares muertos. Véase, por ejemplo, "El Ministerio del Ejercito da a conocer el número total de bajas", Falange, 11 de diciembre de 1957; "Cuarenta y siete muertos entre cabos y soldados", ABC, 24 de diciembre de 1957. Un análisis comparativo entre los datos oficiales y los posteriormente reconocidos puede ayudar a comprender los calificativos de silenciada a la guerra de Ifni. Por ejemplo, en los combates de Edchera, uno de los mayores desastres del conflicto, el ministerio del Ejército reconoció 51 bajas propias, entre muertos y heridos. La realidad es que se produjeron cuarenta y ocho muertos y sesenta y cuatro heridos. Véase "Severa derrota de los agresores marroquíes en el Sahara español", $A B C, 16$ de enero de 1958. El total de muertos en el conflicto entre junio de 1957 y septiembre de 1958 fueron 198, de las cuales 118 fueron en Ifni (Casas de la Vega, 2008: 622; Segura, 2006: 361)
} 
El 30 de diciembre el NO-DO narra en pasado los hechos militares. La guerra parece terminada. El locutor destaca las "constantes pruebas de la brillantez de su actuación" que dieron las fuerzas del Ejército de Tierra, la Aviación y la Marina. Se muestran prisioneros y armamento requisado como pruebas del control de la situación. La amenaza ha desaparecido ${ }^{22}$. En la visita de los corresponsales extranjeros del New York Times, Le Figaro y Paris Match a la zona se insiste en esta narración en pasado del conflicto. En este sentido, el locutor destaca que los periodistas reciben explicaciones de la situación del territorio "después de los hechos de armas" ${ }^{23}$. En enero se reiteraba que "la etapa de los golpes por sorpresa" había concluido. La bandera española ondeando al viento reafirmaba visualmente el control del territorio. El NODO, no obstante, ocultaba que los combates continuaban y que el conflicto se había extendido al Sahara.

Posteriormente, como prueba de la estabilización de la situación, en marzo las imágenes del NO-DO mostraban al ministro de Marina, almirante Felipe José Abarzuza, visitando Ifni, donde inspeccionaba instalaciones y centros militares. El locutor señalaba que esta autoridad había comprobado que la población presentaba "un aspecto completamente normal" ${ }^{24}$. Una vez pacificado el territorio, el noticiario no explicó la decisiva contribución de Francia al fin del problema militar en el Sahara o la entrega de Tarfaya a Marruecos. Asimismo se ocultó que la ocupación efectiva de la colonia española había quedado reducida a la capital Sidi-Ifni y su perímetro de seguridad.

Terminado el conflicto, el NO-DO no vuelve a hacer referencia a los combates en Ifni. Las excepciones son una breve mención a los caídos en tierras africanas durante el Desfile de la Victoria celebrado en 1958 y otra escueta información sobre la entrega de una condecoración póstuma al alférez Rojas Navarrete muerto en combate.

En el primer caso, se reproducen unas palabras del ministro del Ejército, teniente general Antonio Barroso, en las que se recuerda "a los muertos en la Cruzada y a los que dieron su vida en la reciente campaña en tierras africanas". El noticiario también presenta imágenes de los paracaidistas que intervinieron en Ifni acompañados de un texto que no profundiza en los hechos de armas:

El escuadrón de paracaidistas que intervino recientemente en África ostenta una de las representaciones del Ejército del Aire. El paso de estas fuerzas encierra una extraordinaria emoción. También levanta los aplausos del público la bandera de paracaidistas del Ejército de Tierra que luchó en África tomando parte en numerosos combates.

\footnotetext{
${ }^{22}$ N. 782 A, 30 de diciembre de 1957.

${ }^{23}$ N. 782 B, 30 de diciembre de 1957.

${ }^{24}$ N. 794 A, 24 de marzo de 1958.
} 
En el homenaje al oficial de las milicias universitarias muerto el 7 de diciembre de 1957 la narración también resulta aséptica y carente de cualquier intencionalidad explicativa sobre los acontecimientos:

Es descubierto el monumento erigido al alférez Rojas Navarrete, primer oficial de la Milicia muerto en acto de servicio en Ifni y que perteneció a este campamento. Es obra del escultor, alférez también, Don Santiago de Santiago. El ministro del Ejército impone la medalla de sufrimientos por la Patria a la madre del héroe ${ }^{25}$.

La guerra, que nunca fue declarada oficialmente como tal, se define en los guiones de los noticiarios minimizando su relevancia y se utilizan términos explicativos como ataque injusto (779 A), ataque de las bandas armadas (779 B), operaciones militares, agresiones de las bandas armadas (782 A y B), hechos de armas (782 B) u operaciones de castigo (791 B y 792 A). El propio Franco, en su discurso de fin de año ofrecido a través de las imágenes del NO-DO, define el acontecimiento bélico como "agresión armada" (783 B). En la edición 783 A, que también recoge esta alocución navideña, no hay una referencia explícita a Ifni, dada la selección realizada por el montador, pero se reproducen palabras de Franco que señalan, en un mensaje con rasgos apocalípticos propios de los tiempos de la amenaza atómica, sobre una posible guerra que si se encendiese "no conocería límites" y que destruiría "la vida en grandes sectores de la tierra". Es un mensaje amenazante y que sorprendentemente rompe con la estrategia comunicativa global de tratar de minimizar los acontecimientos de $\mathrm{Ifni}^{26}$.

Años después, en el noticiario que en 1962 conmemoraba los primeros 1.000 números del NO-DO y que repasaba los principales hitos informativos desde 1943, esta guerra era descrita una vez más como "las agresiones en Sidi Ifni"27.

\subsection{El Ejército}

A lo largo de la historia del NO-DO la información sobre el ejército fue muy reducida (Tranche y Sánchez-Biosca, 2000: 222). No obstante, en sus escasas referencias, el noticiario siempre transmitió la imagen de un conjunto de fuerzas heroico, disciplinado, eficaz y en disposición permanente para la defensa de la Patria. Asimismo destacó su preparación y su dotación armamentística (Rodríguez Mateos, 2008: 199201). Indudablemente los valores castrenses propios de un ejército institucional y que el noticiario repetía en las apariciones de las tropas en las pantallas cinematográficas eran compartidos por la mayor parte de los mandos y jefes de las fuerzas armadas. Sin

\footnotetext{
${ }^{25}$ N. 818 B, 8 de septiembre de 1958.

${ }^{26}$ El texto del discurso de fin de año en $A B C, 31$ de diciembre de 1957.

${ }^{27}$ N. 1.000 A, 5 de marzo de 1962.
} 
embargo, la exaltación de la fortaleza y de los equipamientos militares tenía un componente claramente propagandístico que no respondía, como puso de manifiesto la guerra de Ifni-Sahara, a la realidad del ejército que combatía en África.

Las fuerzas armadas, pese a su centralidad en la vida política franquista, contaban con una escasa modernización tanto en su organización como en su capacidad armamentística, aunque esta había avanzado gracias a los suministros norteamericanos fruto de los pactos firmados con los Estados Unidos en 1953. Historiadores como Casas de la Vega o Diego Aguirre han señalado, salvando la actuación personal de los miliares, el desorden de la logística y la falta de material adecuado durante la campaña (Cardona, 2003: 280-282). Antiguos combatientes han apuntado a la responsabilidad de las autoridades franquistas, aun siendo conocedoras de la amenaza marroquí, en las limitaciones armamentísticas y logísticas. La política, en este caso el condicionamiento de los Estados Unidos que querían evitar un conflicto mayor en la zona con un aliado como Marruecos, determinaron también las actividades y los medios sobre el terreno (Colldefors, 2007: 47).

El armamento ligero utilizado, aunque algunas unidades contaron con el moderno CETME $A$, era anticuado. Los uniformes y equipamientos resultaban inadecuados 0 incompletos (Canales y Del Rey, 2010: 237-245). El Ejército del Aire disponía de material moderno, como los aviones F-86 Sabre, suministrados por los Estados Unidos, pero su uso fue impedido por el acuerdo que imposibilitaba su empleo contra países aliados de Norteamérica (Platón, 2001: 244-245) ${ }^{28}$.

En cualquier caso, en los noticiarios relacionados con la guerra de Ifni-Sahara no se exaltó el equipamiento militar sino la eficiencia, la preparación y las virtudes castrenses de las tropas. Las imágenes testimoniaron, algunas veces con cierta habilidad fílmica como, por ejemplo, en el caso del noticiario 791 B, esta profesionalidad y eficacia. Las diferentes unidades del ejército destacaron por "el patriotismo, el arrojo y la combatividad" de sus integrantes. Las tropas dieron muestras "del temple y de la bravura de nuestra raza" o se excedieron en "el cumplimiento de su deber sin reparar en peligros y fatigas". El noticiario también resaltó la coordinación entre las distintas fuerzas de los ejércitos. Los testimonios posteriores de los combatientes parecen desmentir este relato fílmico sobre la organización de las fuerzas armadas, aunque las tropas, pese a todas sus limitaciones, indudablemente dieron muestras de heroísmo y los mandos ejercieron adecuadamente su labor. Los informativos cinematográficos, en cualquier caso, obviaron explicar la contribución militar de Francia a la resolución favorable de la guerra.

\footnotetext{
28 La decisión de no utilizar material norteamericano parece que también fue española. En las operaciones, no obstante, se emplearon aviones de transporte DC-3, carros de combate M- 24 y aviones T-6 (López-Pozas, 2013: 88-89).
} 
Una vez que el conflicto quedó solucionado, resulta sorprendente la exaltación del equipamiento militar de las fuerzas armadas que realizó el NO-DO en la narración sobre la celebración del Desfile de la Victoria en el mes de mayo de 1958. Mientras que las tropas habían padecido las limitaciones del equipamiento en Ifni, los textos e imágenes del NO-DO presentaban "el moderno material", la "potencia y poderío" de las fuerzas acorazadas o, por primera vez, los nuevos cañones que podían disparar "proyectiles de cabeza atómica"29.

\subsection{El papel de Marruecos}

Una de las principales líneas argumentales del NO-DO acerca de Ifni fue la defensa de la legitimidad de la soberanía española sobre el territorio africano. En los noticiarios se justificaron los derechos de España citando el tratado con Marruecos alcanzado en 1860. El NO-DO recordaba que el final del protectorado y la independencia marroquí no afectaban a la soberanía española sobre $\mathrm{Ifni}^{30}$.

Una vez afirmados los derechos de nuestro país frente al reino magrebí, el noticiario optó por mantener el mito de la amistad hispano-marroquí y negar las vinculaciones, que parecen históricamente ya demostradas (Diego Aguirre, 1990: 16), entre los atacantes y Marruecos. El discurso respondía al patrón oficial que ocultaba el amparo de Mohamed $\mathrm{V}$ a los agresores ${ }^{31}$. La agresión de las bandas armadas se había realizado "al margen de cualquier obediencia efectiva al gobierno de Rabat"32.

No obstante, el 30 de diciembre el NO-DO ofreció datos puntuales que sugerían los lazos de los agresores con el territorio magrebí. El noticiario destacaba que los integrantes del Ejército de Liberación procedían "de la zona de Marruecos" y que las armas y municiones capturadas al enemigo eran, en su mayor parte, procedentes de las entregas realizadas por España a Marruecos en 1956. En cualquier caso, siguiendo la línea informativa oficial, el NO-DO evitó una acusación directa contra el país magrebí.

En el discurso del fin de año de 1957, Franco explicó, utilizando un lenguaje ampuloso y difícilmente entendible por los espectadores de los noticiarios, que el problema debía ser resuelto por Marruecos ${ }^{33}$. Si el reino magrebí permitía actuaciones contra el

\footnotetext{
${ }^{29}$ N. 801 B, 12 de mayo de 1958.

${ }^{30}$ N. 779 B, 9 de diciembre de 1957.

${ }^{31}$ En $A B C$, Arriba o la revista África también se exculpa, siguiendo el discurso oficial del Régimen, a Mohamed $V$ de la responsabilidad en los ataques del Ejército de Liberación (Pérez García, 2006: 185188).

${ }^{32}$ N. 779 A, 9 de diciembre de 1957.

${ }^{33}$ N. 783 B, 6 de enero de 1958.
} 
derecho peligraba "la efectividad real del Estado y hasta la existencia misma de ese mismo pueblo como comunidad política verdaderamente soberana". A continuación, el Caudillo, en unas palabras con notas de contenido teológico-político, mostraba la voluntad de mantener la amistad hispano-marroquí: "España y Marruecos, colocados por la mano de Dios en una misma área geográfica del Mediterráneo occidental y de la región atlántica, están llamados a entenderse por la naturaleza."

\subsection{El enemigo}

El enemigo, de acuerdo con la narración del noticiario, eran bandas armadas o bandas irregulares del "llamado Ejército de Liberación" o del "mal llamado Ejército de Liberación" ${ }^{34}$. EI NO-DO resaltaba que este estaba integrado por combatientes ajenos a los territorios de Ifni y que no contaban con el respaldo de los indígenas. Las tribus de Ifni seguían "fieles a España" 35 . Los agresores habían sido obligados a combatir forzosamente. Procedían "en su totalidad de la zona de Maruecos". Junto a la referencia al enrolamiento no voluntario de los integrantes de las bandas irregulares, se señalaba que estos "cobraban de quince a veinte mil francos al mes" ${ }^{36}$.

Finalizado el conflicto, el ministro del Ejercito, teniente general Barroso, también hizo referencia, durante su visita a Ifni, al enemigo de la población autóctona como "Ios perturbadores venidos de fuera" ${ }^{37}$. En el mismo noticiario se apuntaba que los indígenas habían hecho patente al ministro "su protesta contras las agresiones de que habían sido victimas durante las incursiones de las bandas armadas".

Estas afirmaciones contienen, pese a su carácter inequívocamente propagandístico, una evaluación parcialmente correcta de la realidad de la población ifneña y saharaui. Parte de las tribus saharauis eran fieles a España (Casas de la Vega, 2008: 299-300). Los Ulad Delim, la tribu más importante del sur del Sahara, y los Izarguien habían expresado su decisión de no combatir a España. Los Erguibat, sin respaldar en su totalidad a Marruecos, combatieron junto al Ejército de Liberación. Los saharauis no mostraron un apoyo activo a las posiciones españolas, entre otras razones, por el miedo a posibles represalias marroquíes ante un presentido abandono del territorio por parte de nuestro gobierno. En Ifni, sin embargo, existía un sentimiento favorable a Marruecos alentado por las oficinas del partido nacionalista Istiqlal ubicadas en la misma capital del territorio español. Numerosos baamaranis se unieron a los agresores. Por otra parte, algunos nativos, como señalaba el noticiario, fueron, aunque

\footnotetext{
${ }^{34}$ N. 784 A, 13 de enero de 1958.

${ }^{35}$ N. 784 A, 13 de enero de 1958.

${ }^{36}$ N. 782 A, 30 de diciembre de 1957.

${ }^{37}$ N. 796 A, 7 de abril de 1958.
} 
su número era pequeño, reclutados a la fuerza o como mercenarios (Bataller, 2012: 41-42).

En relación al enemigo resulta relevante, como se ha observado anteriormente y que diferencia el tratamiento informativo del NO-DO respecto a otros medios de comunicación, la ausencia de referencias al comunismo como responsable último del conflicto. No obstante, en las palabras del discurso de fin de año ofrecidas por el NODO, Franco señaló, utilizando la retórica habitual del discurso anticomunista franquista propio de los años de la guerra fría, que España tenía "la responsabilidad histórica de constituir el centinela avanzado" de Occidente en esa región africana ${ }^{38}$.

\section{Colonización y retrocesión}

La primera referencia a Ifni en el NO-DO aparece en el reportaje $408 \mathrm{~A}$ dedicado a la visita de Franco al África Occidental Española en 1950. En este primer tratamiento informativo sobre el territorio se exaltó la labor colonizadora de nuestro país utilizando el tono paternalista propio del africanismo español. El noticiario señalaba que los indígenas expresaban el cariño a España "por las preocupaciones y desvelos" que nuestro país había puesto "en lo que hace unos años era un país inhóspito y vacío". "El régimen que no descansa" había construido la villa soñada por el coronel Capaz.

El mensaje sobre la labor colonizadora retornó a los noticiarios coincidiendo con el inicio del conflicto bélico en 1957. El NO-DO trató de demostrar que la guerra contra España era injusta. Como se ha señalado, frente a las agresiones de las bandas armadas ajenas a los verdaderos pobladores de Ifni, el NO-DO describió la contribución española a la civilización de unos territorios pobres y desérticos. Las dos ediciones del noticiario del 9 de diciembre de 1957, primeros reportajes que tratan sobre el conflicto bélico, narran ampliamente esta labor. De acuerdo con el guión, antes de la llegada del coronel Capaz a Sidi Ifni en 1934 los nativos vivían "rodeados de miseria". España había transformado una "alcazaba semiderruida" en una moderna ciudad "incorporada al progreso y a la civilización". A lo largo de veinte años se había realizado "una intensa labor de progresos sanitarios, técnicos y administrativos" en todo el territorio ifneño. Los beneficiarios de esta "desinteresada empresa de colonización" eran las

\footnotetext{
${ }^{38}$ En el discurso de fin de año, aunque no en los fragmentos utilizados por el NO-DO, Franco hace una referencia expresa a los "agentes soviéticos" que pretendían penetrar en los territorios africanos "a caballo de los ultranacionalismos exacerbados".
} 
poblaciones indígenas. Además, esta acción civilizadora se había desarrollado ejemplarmente respetando la religión y costumbres de los nativos ${ }^{39}$.

Una vez pacificado el territorio, sorprende la fuerte inversión en infraestructuras del gobierno español en la capital Sidi Ifni. La mayor parte de las escasas referencias posteriores a la colonia están relacionadas con las obras públicas desarrolladas por España y con las visitas de las autoridades y ministros para comprobar el avance de estos trabajos. Este afán constructivo tenía su lógica ya que después de la guerra creció el número de habitantes, sobre todo funcionarios y militares, en la colonia y, por tanto, surgió una necesidad de viviendas y otras infraestructuras. La población europea de Sidi Ifni pasó de 2.267 a 11.984 personas en el periodo 1950-1967 (Gozálvez, 1994: 55-61). Los indígenas, no obstante, también se beneficiaron de los esfuerzos en atención educativa, sanitaria y otros servicios ${ }^{40}$.

En 1958 el NO-DO es testigo de las operaciones para la construcción del embarcadero que ha de facilitar el desembarco de personas y mercancías en la abrupta costa ifneña ${ }^{41}$. Esta peculiar construcción que consta de un funicular regresará a las pantallas del noticiario en 1961 para mostrar los avances en la obra ${ }^{42}$. Posteriormente, el NODO, en línea con el discurso de la eficacia del Estado en el desarrollo de sus provincias, relata las visitas del ministro de Obras Públicas en $1959^{43}$, de Carrero Blanco en $1962^{44}$ y del ministro de Información y Turismo, Manuel Fraga Iribarne, en $1966^{45}$.

La última referencia a Ifni en las pantallas del NO-DO coincidió con la información sobre la ceremonia de retrocesión de la colonia al reino de Marruecos celebrada el 30 de junio de $1969^{46}$. Ni la guerra ni los caídos en combate fueron recordados. No se ofreció una explicación sobre el cambio de posición en relación a los derechos españoles sobre el territorio africano, que habían sido repetidamente recordados once años atrás. Incluso el narrador destacaba que Ifni se devolvía a Marruecos, lo que implica una soberanía previa del reino magrebí. El NO-DO siguió nuevamente el discurso oficial que minimizó la relevancia de la retrocesión ${ }^{47}$. El relato del

\footnotetext{
${ }^{39}$ N. 779 A y B, 9 de diciembre de 1957.

${ }^{40}$ Por ejemplo, sobre una población indígena de 5.662 personas, en 1968 había 194 alumnos nativos en la Escuela Laboral y 17 en el Instituto de Ifni (Gozálvez, 1994: 59). En 1963, 784 africanos fueron atendidos hospitalariamente (Sahara- Ifni, 1964: 184).

${ }^{41}$ N. 825 A, 27 de octubre de 1958.

${ }^{42}$ N. 953 B, 10 de abril de 1961.

${ }^{43}$ N. 840 B, 9 de febrero de 1959.

${ }^{44}$ N. 1.035 C, 5 de noviembre de 1962

${ }^{45}$ N.1.215 A, 18 de abril de 1966

${ }^{46}$ N. 1.384 B, 14 de julio de 1969.

${ }^{47}$ Sobre el impacto de la devolución de la colonia en la sociedad española véase González Sáez, 2012.
} 
acontecimiento, al que significativamente se le dedican más de cuatro minutos, duración en relación a la información de los noticiarios sobre Ifni solo superada por el relato del primer viaje de Franco a la colonia, relata la contribución desinteresada de España al desarrollo y ayuda de los nativos. Pese a esta atención en términos de metraje, la narración resulta, como se ha indicado, escasamente interpretativa de los acontecimientos y evasiva, aunque no elude mostrar cómo se arría la bandera nacional, tratando de minusvalorar la pérdida de un territorio del que se resalta su carácter pobre y desértico.

\section{Conclusiones}

Ifni, territorio ocupado por España en 1934, tuvo escasa presencia en los noticiarios del NO-DO, reflejo de la baja relevancia demográfica y económica de la colonia. Sobre un total de 3.309 noticiarios entre 1943 y 1969 las ediciones con referencia explícitas a Ifni se limitan tan solo a 26 . Es decir, menos del $1 \%$ del total de ediciones contuvieron una mención a la colonia.

La mayor atención informativa se concentró en el periodo 1957-1958 coincidente con la guerra que el Ejército de Liberación lanzó contra el territorio español. La guerra se mostró públicamente en las pantallas de los cines, no fue silenciada, pero la imagen ofrecida, sometida a control oficial, no respondió a la dura realidad del conflicto ni a los problemas militares para controlar la situación. Este enfoque, independientemente del carácter autoritario del régimen franquista, no constituye una excepcionalidad al tratamiento informativo de los conflictos bélicos por parte de los noticiarios de la época en otros países.

El NO-DO ofreció contenidos con tratamientos superficiales $y$, en muchos casos, evasivos, en sintonía con la estrategia informativa restrictiva del gobierno y con las propias características de los noticiarios que mantenían una menor tensión propagandística en comparación con otros medios. Los ejes de comunicación se basaron principalmente en la justificación de de la legitimidad de la soberanía española sobre los territorios africanos, en la defensa de la labor civilizadora desinteresada de nuestro país y, desde el punto de vista militar, en la exaltación del patriotismo, coraje y preparación de las fuerzas armadas. El papel de Marruecos como nación agresora o la lógica participación de muchos indígenas en las fuerzas enemigas fueron, como en el resto de medios de comunicación españoles, minimizados $u$ ocultados. EI NO-DO, en definitiva, en un contexto bélico, no trató de movilizar ni exaltar a la población con mensajes propagandísticos agresivos sino que aprovechó su influencia social para transmitir, en línea con el discurso oficial, serenidad, tranquilidad y control de la situación. 
Con posterioridad a la guerra, la presencia de Ifni en las pantallas del NO-DO es muy escasa limitándose a unas pocas noticias que, desde un permanente enfoque paternalista propio del africanismo español, remarcaban las tareas civilizadoras de nuestro país. La última referencia fue el aséptico reportaje dedicado a la retrocesión de Ifni a Marruecos en 1969. El noticiario se mostró alineado con el objetivo político de minusvalorar la relevancia del abandono de un territorio, una provincia española, en cuya defensa había muerto más de un centenar de soldados pocos años antes.

Esta investigación queda abierta a ser revisada y ampliada, por ejemplo, con análisis comparados del tratamiento informativo de otras colonias y territorios españoles. En este sentido, el acceso a los archivos del NO-DO a través de internet es indudablemente un facilitador para nuevos estudios históricos basados en la riqueza documental de los noticiarios cinematográficos.

\section{Referencias bibliográficas}

ALONSO DEL BARRIO, José Enrique (2010): Sáhara-Ifni. ¿Encrucijada o abandono? 1956-1963, Zaragoza, Mira Editores, 2 volúmenes.

BATALLER ALVENTOSA, Vicente (2012): Tiradores de Ifni. La guerra de Ifni en imágenes. De la Rebelión a la Posguerra. 1956-1969, Madrid, Almena.

CANALES, Carlos y DEL REY, Miguel (2010): Guerra de Ifni-Sáhara. 1957. La última guerra española, Madrid, Nowtilus.

CARDONA, Gabriel (2003): El gigante descalzo. El Ejército de Franco, Madrid, Aguilar.

CASAS DE LA VEGA, Rafael (2008): La última guerra de África (Campaña de Ifni-Sáhara), Madrid, Ministerio de Defensa.

COLLDEFORS VALCÁRCEL, José (2007): “Conclusiones de la guerra de Ifni-Sahara (195758)" en Boina Negra, Extraordinario 50 aniversario IFNI-SAHARA, 252, pp. 46-49.

CORREALE, Francesco (2011): "La "última guerra colonial" de España y la literatura militar entre memoria y conocimiento" en Actas 70 Congreso de Estudios Africanos, Lisboa. Disponible en internet (10-07-2013): htpp//www.repositorioiul-iscte.pt/bitstream/10071/2326/1//CIEA7_21_CORREALE_La última guerra colonialdeEspañaylaliteraturamilitar.pdf.

DE LA SERNA, Alfonso (2001): Al sur de Tarifa. Marruecos-España: un malentendido histórico, Madrid, Marcial Pons. 
DIEGO AGUIRRE, José Ramón (1990): “Ifni, la última guerra colonial española" en Historia 16, 167, pp. 16-37.

(1993): La última guerra colonial de España: Ifni- Sahara (1957-1958), Málaga, Algazara.

FERNÁNDEZ-ACEYTUNO, Mariano (2001): Ifni y Sáhara. Una encrucijada en la historia, Dueñas, Simancas.

FRANCO SALGADO-ARAUJO, Francisco (1976): Mis conversaciones privadas con Franco, Barcelona, Planeta.

GÓMEZ MARTÍNEZ, Pedro, J. y ENCINAR LÍAS, Ana Elisa (2010): “Conflictos armados y comunicación. La estrategia persuasiva en el contexto bélico español" en Revista Comunicación y Hombre, 6, pp. 65-82.

GONZÁLEZ SÁEZ, Juan Manuel (2012): “La retrocesión de Ifni: opinión pública y oposición política" en Martínez, Leandro (ed.), La presencia española en África. Del "fecho de Allende" a la crisis de Perejil, Madrid, Universidad Rey Juan Carlos, pp. 189-214.

GOZÁLVEZ PÉREZ, V. (1994): “Descolonización y migraciones desde el África española (1956-1975) en Investigaciones geográficas, 12, pp. 45-84.

HERNÁNDEZ, Miguel Ángel (2003): Estado e Información: el NO-DO al servicio del Estado Unitario (1943-1945), Salamanca, Universidad Pontificia de Salamanca.

JORQUES ORTIZ, Manuel (2011): Historias secretas de Ifni. Hablan los soldados, Doña Mencia, autor-editor.

LÉON, José Luis (1989): Persuasión de masas. Psicología y efectos de las comunicaciones sociopolíticas y comerciales, Bilbao, Deusto.

LÓPEZ-POZAS LANUZA, José Carlos (2013): “La guerra de Ifni-Sahara (1957-1958) y el conflicto del Sahara de 1975" en Revista Universitaria de Historia Militar, 3, pp. 72-93.

MADARIAGA, María Rosa de (2013): Marruecos, ese gran desconocido. Breve historia del protectorado español, Madrid, Alianza.

MORALES LEZCANO, Víctor (1991): "La descolonización del Norte de África en perspectiva histórica" en Espacio, Tiempo y Forma, 4, pp. 171-180.

(2006): Historia de Marruecos. De los orígenes tribales y las poblaciones nómadas a la independencia y la monarquía actual, Madrid, La esfera de los libros. 
PAZ, María Antonia y SÁNCHEZ, Inmaculada (1999): "La historia filmada: Ios noticiarios cinematográficos como fuente histórica. Una propuesta metodológica" en Film Historia, vol. IX, no 1, pp. 17-33

PÉREZ GARCÍA, Guadalupe (2003): "La falacia histórica sobre la colonia de Ifni" en Historia y Comunicación Social, 8, pp. 207-222.

(2004): "La cobertura de NO-DO sobre el colonialismo español en África: de la Guerra de Ifni-Sáhara a la Marcha Verde" en Pena, Alberto (Ed.): Comunicación y guerra en la historia, Santiago de Compostela, Tórculo Edicións.

PÉREZ GARCÍA, Guadalupe (2006): “La guerra de Ifni y la falsa culpabilización al comunismo internacional por parte del régimen franquista" en $Z E R, 20$, pp. 179196.

(2006b): “A.O.E. Semanario Gráfico de África Occidental Española” en Revista Historia y Comunicación Social, 11, pp. 83-97.

PINIÉS Y RUBIO, Jaime de (2001): La descolonización española en las Naciones Unidas. Guinea Ecuatorial (Fernando Poo y Río Muni), Ifni, Sahara Occidental, Gibraltar y las Naciones Unidas, Madrid, Centro de Estudios Políticos y Constitucionales.

PLATÓN, Miguel (2001): Hablan los militares, Testimonios para la historia (1939-1996), Barcelona, Planeta.

RODRÍGUEZ, Saturnino (1999): El NO-DO, Catecismo social de una época, Madrid, Complutense.

RODRÍGUEZ MATEOS, Araceli (2008): Un franquismo de cine. La imagen política del Régimen en el noticiario No-Do (1943-1959), Madrid, Rialp.

RUIZ MIGUEL, C. (1995): El Sahara Occidental y España: Historia, política y derecho. Análisis crítico de la política exterior española, Madrid, Dykinson.

Sahara- Ifni (1964), Madrid, Publicaciones Españolas.

SEGURA VALERO, Gastón (2006): Ifni. La guerra que silenció Franco, Madrid, Martínez Roca.

SUÁREZ, Luis (2005): Franco, Barcelona, Ariel.

TRANCHE, Rafael R. y SÁNCHEZ-BIOSCA, Vicente (2000): NO-DO. El tiempo y la memoria, Madrid, Cátedra/Filmoteca Española.

VIDAL, LORENZO M. (2006): Ifni: La prensa y la guerra que nunca existió, 1957-1958, Madrid, Almena. 
VILAR, Juan B. (2000): "La descolonización española en África”, en Tusell, J., Avilés, J. y Pardo, R. (eds.), La política exterior de España en el siglo XX, Madrid, Biblioteca Nueva, pp. 391-410.

YBARRA ENRÍQUEZ DE LA ORDEN, María Concepción (2007): “Fuentes archivísticas para el estudio de la independencia del Magreb" en Vidal Galache, Florentina (coord.): Testigos de la Historia. Estudios sobre fuentes documentales, Madrid, Fundación Carlos de Amberes, pp. 165-189.

ZUNZUNEGUI, Santos (1984): Mirar la imagen, San Sebastián, Universidad del País Vasco. 